\title{
Sunday Sounds
}

\section{Preserving the Radio Ministry of Brooklyn's Bethany Baptist Church \\ Colleen Bradley-Sanders, Brooklyn College}

\begin{abstract}
Rev. Dr. William Augustus Jones, Jr. was pastor of Brooklyn's Bethany Baptist Church for over forty years and a significant figure in the African-American community. In the mid-1970s New Jersey radio station WFME approached him with an offer to have his Sunday sermons broadcast as The Bethany Hour in the New York, New Jersey, and Connecticut markets. Brooklyn College Archives has the Jones collection, which contains cassette recordings of several hundred of these sermons, as well as video recordings from the program's short time on broadcast television. With no playback equipment for patrons, and concerned about the physical integrity of the recordings, the Archives decided to digitize the materials. With a tight budget and no digitization expertise on staff, the Archives applied for and won a Council on Library and Information Resources Recordings-at-Risk grant. Despite some delays due to the COVID-19 pandemic, the project was made available to the public at the end of March 2021.
\end{abstract}

I'm going to tell you about how the Archives at Brooklyn College handled what was for us a large audio-visual collection, in a setting with limited capacity for patrons to watch or listen to such materials. First, a little background.

For the past fifty years, archivists have heeded the call of historian Howard Zinn, who challenged the profession to document the lives, needs, and desires of ordinary people, to look beyond the traditional and narrow focus on official records and "important" people. Documenting the lives of underrepresented groups such as religious and ethnic minorities became part of the focus in our overwhelmingly White profession, although African-Americans have been documenting their own history since before the Civil War.

At Brooklyn College, we document diversity not only through collecting the records of our faculty and alumni, but also through acquiring the archives of people and organizations in the multicul- 
tural borough of Brooklyn. One such collection is that of the Rev. Dr. William Augustus Jones, Jr.

A native of Kentucky, Rev. Jones became the pastor at Brooklyn's Bethany Baptist Church in 1962 and remained there for 43 years until his retirement in 2005. He was a respected figure not only in his community, but around the world. He preached at St. Patrick's Cathedral in New York City, the International Congress on Preaching in Scotland, and at the first All-Asian Baptist Church Congress in India. He taught pastoral courses at a number of seminaries, including Colgate Rochester Divinity School, Union Theological Seminary in New York City, and Princeton Theological Seminary, among others.

A tireless champion for economic and social justice, Jones co-founded the Progressive National Baptist Convention with Dr. Martin Luther King, Jr., succeeded Rev. Jesse Jackson as chair of the Southern Christian Leadership Conference's Operation Breadbasket, led local boycotts against businesses that discriminated against African Americans, and used his ministry as a platform to encourage his congregation to participate in political elections and the broader social movements in the country. A prominent figure who gave invited talks throughout the U.S. and the world, he was approached by New Jersey radio station WFME in 1975 with an offer to broadcast his weekly Sunday sermon. The sermons were recorded at the church, and the tapes were then taken to the station for broadcasting the following week, under the name The Bethany Hour. While these transmissions were initially limited to audiences in the Tristate area (that's New York, New Jersey, and Connecticut), Jones's recorded sermons were soon distributed to stations in other parts of the country and heard by thousands of listeners throughout the nation. The program continued into the early 2000 s.

Through a connection with Brooklyn College student Kojo Davis, a member of Rev. Jones' congregation, the Brooklyn College Archives acquired the papers of Rev. Jones as a donation from his family. Davis was a student of Africana Studies professor Lynda Day, who contacted the archive after Jones's death in 2006 about the possibility of us accepting his papers. Jones's family felt the Archives' focus on Brooklyn history made it a good fit for this collection, since the reverend's ministry had been centered in Brooklyn for over forty years. The collection contains records of Jones's church and community activities, and over 700 recordings of The Bethany Hour as well as a few other sermons by Jones. The recordings are on audiocas- 
sette, quarter-inch audio tape, VHS, and Betamax videotape. None of them are masters.

The collection was acquired as part of a conscious effort to document the lives of everyday individuals traditionally underrepresented in mainstream archives, and in recognition of its historical and cultural value. There is a responsibility that goes along with accepting a collection - to not only provide access to it, but also to ensure its preservation. However, despite the Jones collection's appropriateness for the Archives' collecting mission, the staff's limited experience working with audiovisual records, particularly digitizing them, a limited budget, and concern about patrons using the original cassettes and videotapes posed challenges for the adequate care of, and patron access to, the recordings.

Although the initial processing of the collection had some deficiencies, it was opened to researchers in 2008 , with the exception of the audio-visual materials. These deficiencies, including unnecessary retention of non-archival artifacts (such as Rev. Jones' straw hat) and lack of any detailed information regarding the recordings, led to my decision to order reprocessing of the collection in 2018. Since assuming my position at Brooklyn College in 2015, my main priorities have been to reduce the backlog of unprocessed collections and make materials more easily available to researchers. For certain collections, such as Jones's, this meant digitizing some materials, which, given the Archives' budget situation, meant securing outside funding.

In order to write a successful grant application, I had to make a valid argument as to the research value of the collection, and part of developing that argument meant researching what collections of this type already existed. The answer was surprisingly few. There are countless entertainment or sports-related recordings, but everyday religious services are hard to find.

We believe this collection offers opportunities for study not only to seminary students, but scholars in political science, history and other humanities disciplines examining the topics of the social gospel, the interplay of Christianity and social justice, the intersection of politics and religion, and the relationship between Evangelical faith and social action, to name a few. While there is considerable interest in the Christian right and White evangelicals, the history of Black evangelicals, often progressive and forward thinking, is not as wellknown and appreciated. 


\section{SECURING GRANT FUNDING}

As I mentioned, the Bethany Hour recordings, none of which are master copies, date to 1975, and their storage media had reached or long exceeded their projected lifespans. Due to their age, we were concerned about playing the audio cassettes and VHS tapes, and we did not even have the capacity for playing the Betamax tapes or quarter-inch audio reels.

Preserving them for future use was critical, so we applied for a CLIR (Council on Library and Information Resources) Recordingsat-Risk grant because of the program's focus on digitizing rare and unique audiovisual materials with strong research value. The grant limit of $\$ 50,000$ was perfect for our project. While I developed my argument as to the significance of the materials, we also inventoried them to support future metadata creation and to identify duplicate recordings or recordings unrelated to The Bethany Hour or other sermons by Jones.

Granting agencies want to know how you're going to make potential users aware of the project they're funding, so as I worked on the grant application, I contacted Christine Fruin at Atla. At first it was to see if Atla would be interested in linking to the digitized materials, and then I sought advice on how to estimate the time needed for the various steps of digitizing, creating metadata, and uploading the files. We planned to hire a Project Archivist and had to calculate the salary for the grant application. Christy Karpinski was very helpful with that aspect of our application. As we worked together, Christine suggested adding the collection information to the Atla Digital Library, which would point users back to Illumira.net, the site hosting the college's digital audio and video content. Atla would harvest the metadata from Illumira. To facilitate this Christy asked that we use the Qualified Dublin Core metadata schema.

I solicited digitization proposals from three vendors and ended up selecting Iron Mountain based on their ability to meet all requirements related to media formats and digital file specifications, their cost estimate, and their strong reputation. The digitization and Project Archivist costs resulted in a grant request for just over $\$ 41,000$. Letters of support came from two Brooklyn College professors who had used documents from the Jones collection, and the retired President of Colgate Rochester Crozier Divinity School. 
They wrote about Jones's influence and helped define for the funding agency the importance of the collection and why digitization was required to provide complete access. We emphasized in the application that although the Archives do hold Jones's papers, there are very few extant transcripts of the sermons, and therefore to know what this man said to his congregants requires one to listen to the recordings. Although we were limited to three letters of support, in my argument for the research value of the collection I did incorporate some thoughts from the then-President of the NY Theological Seminary, Dale Irvin, who said, quote "Rev. Jones is under-recognized in the wider scholarship of the history of the Civil Rights movement precisely because he is under-recognized for his preaching." His sermons have been included in books on both preaching (Preaching with Sacred Fire: An Anthology of African American Sermons, 1750 to the Present) and civil rights (Civil Rights Voice for the Oppressed: The Story of Rev. John L. Scott). Scott's book opens with an acknowledgement of the impact Rev. Jones' preaching had in advancing the Civil Rights movement. Dr. Irvin also noted that Jones' preaching style was remarked upon more so than the content of his sermons. Our project to make Jones' words accessible addresses that hole in the scholarship of both preaching and the Civil Rights movement.

We did decide to digitize one non-sermon. It is a 1983 interview from the television show "Way to Go" with Rev. Jones and a Rev. Darryl George. The host, Dr. James P. Carse, interviews Jones and George about the connection between social and economic issues and the teachings of the church. They also discuss the history of Bethany Baptist Church as well as Jones' history of activism including Operation Breadbasket.

Our first grant application was denied in April 2019, but the reviewers felt the project was a worthwhile endeavor and encouraged us to reapply during the next funding cycle. The main areas of the application that needed strengthening were the technical details of the digitization, proving Brooklyn College had the right to put the sermons online (which was stated in the original application), and revising the original plan to discard the physical recordings once digitized. The plan to discard the originals was an error on my part, due to lack of familiarity with AV collections, and a desire to create some more space in a very crowded archive. We easily addressed the reviewers' technical concerns and resubmitted the application. The 
technical concerns included questions about sampling frequency for the audio, the parameters for the video digitization, specifically the pixel dimensions, wrapper, and whether the digital files would retain the resolution of the source materials, and also if the specifications were adequate for long-term sustainability. We were awarded a grant in October 2019. Project work began in December 2019 with the plan to digitize and make publicly accessible over 700 sermons by October 2020. Given the kind of year 2020 turned out to be, it should not surprise anyone that the target completion date was later pushed back by six months after we requested an extension from CLIR.

In some ways we were fortunate with the timing of the project. Preliminary work in capturing metadata and preparing the materials for shipment was completed in January 2020, and the recordings were shipped to Iron Mountain well before Brooklyn College shut down in mid-March last year.

We received digitized samples in February 2020 for quality control checks, found them to be good, and gave the go-ahead to finish the project. We had expected to receive the completed files in early May, even with a handful requiring some remediation (repair of tapes snapped during playback or separated from the supply/take up reels in the cassette shell), but instead we found ourselves in a global pandemic that brought people's work and personal lives to a near stand-still.

March 12, 2020, was unexpectedly our last day at work on the $\mathrm{BC}$ campus. We had no idea that after leaving work on the twelfth the Archives staff would not be back on campus for nearly two years, with the exception of very few visits by myself and the Associate Archivist. While there will be a limited staff presence in the fall of 2021, Brooklyn College is not expected to return to full staffing until late January 2022. The Archives will only have one person on campus per day in the fall, and research appointments will be two days per week by appointment only, and restricted to Brooklyn College faculty, staff, and students. Iron Mountain's Pennsylvania location meant they were also affected by that state's shutdown. However, despite the challenges of working remotely, the staff at Iron Mountain were able to complete the digitization work for us by late June 2020 . 
New York City was in terrible shape in the spring of 2020, and our Project Archivist took the opportunity to move to Georgia. We also employ her as a part-time staff member, so while she waited for the digital files from Iron Mountain, she worked on other projects for us. By the end of June, the Project Archivist was able to start work on uploading all the files to the Illumira site. There are approximately 1,100 recordings, as Sides A and B of an audio cassette were digitized as individual files. In addition to creating the metadata and uploading the files, the Project Archivist continues to write short abstracts of each recording, to aid researchers in quickly understanding the general content of a sermon. Because most of the recordings are full Sunday services, the abstracts also note the starting time for the actual sermons.

\section{IMPACTS OF THE PANDEMIC}

The biggest impacts of the pandemic on the project were the nearly two-month delay in receiving the digital files and the complete lack of access to the Brooklyn College campus. The lack of access to the campus affected many aspects of the project, which slowed down and interrupted the workflow. The Project Archivist worked remotely, using a personal laptop computer rather than the computer in the Archives. The smaller screen and her desk and chair setup were less comfortable, which made a difference when doing a large amount of data entry. Her internet service was not as robust and reliable as that at the college, which increased the time needed to upload the video and audio files.

The inability to work onsite at the Archives also slowed down response times when the Project Archivist had questions. She was set to have a training session with the library staff member responsible for managing the library's digital platform, but the College shutdown on March 13 prevented the training from taking place. Subsequently, the same staff member was extraordinarily busy assisting faculty during the spring and summer with the transition to remote teaching and putting course materials on Blackboard, and so was slower to respond to her inquiries about uploading files and using the platform. That situation continued until the end of the project in March 2020. Questions for the Archivist on project specifics had to be answered via email or phone, rather than a quick in-person office visit. 
Once the Project Archivist received the hard drive with the digitized recordings, she checked the digital files against the list of physical recordings, and discovered a few missing, which the vendor took care of and sent to her.

These delays prompted us to request a time extension from CLIR in August 2020. They gave us a standard six-month extension. One non-pandemic related slowdown was the need to put all the metadata into a CSV file in addition to entering it into our digital platform.

In working with Atla to ensure she was capturing the metadata required for the Digital Library, the Project Archivist and Christy Karpinski tested whether the college's platform would support OAIPMH (Open Archives Initiative Protocol for Metadata Harvesting, a mechanism for repository interoperability) for the data harvesting, and unfortunately it does not which meant the creation of a spreadsheet for the metadata. The Illumira platform also does not permit uploading of metadata by CSV; each field must be filled individually, by typing or copy and paste from a spreadsheet. Some reformatting of the CSV data was necessary to get it to conform to the requirements of Atla's system, but the problems were quickly resolved in consultation with Atla.

The results of the project can be seen on the Illumira site, which hosts the Archives' digital content: https://brooklyn.illumira.net/showcollection.php?pid=njcore:169222

The home page of the Brooklyn College Archives on the Illumira platform shows all of the Archives' digital resources, not just the 1,125 of the Jones Collection. One of the limitations of this platform is that we cannot separate different collections other than as can be seen on the right of the home page in the listing of "sub-collections." The search function will find the search term in either a title or an abstract. For example, searching the term Martin pulls up three results, one of them a sermon titled No Greater Love.

Search results:

https://brooklyn.illumira.net/search.php?query=Martin\&orgquery =Martin\&cname=njcore $\% 3 \mathrm{~A} 168116$ 
"No Greater Love"

https://brooklyn.illumira.net/show.php?pid=njcore:180838

The abstract shows this sermon is about the death and funeral of Martin Luther King, Jr. The episode is from Jan 27, 2002. This one is a video. The bulk of the recordings are audio only, but in its later years The Bethany Hour moved from radio to television, so we have some video.

Under the attachments tab is a link to a PDF transcript of the recording:

https://brooklyn.illumira.net/streamer.php?pid=njcore: 180838\&ds=SUPP-1

The transcripts are not part of the grant deliverables. As we worked on the application, and communicated with the Jones family about the project, they offered to contribute some money to it. Since there are almost no paper copies of the sermons in Rev. Jones' papers, I immediately thought of adding sermon transcripts to the collection to make it easier for researchers to study them. I told the family that as we got to the stage of the project where transcripts could be made, we could talk further about a donation.

When the college shut down last year, I wondered how in the world I'd keep my staff busy. Archival work is very hands-on, even when digitizing content. Well, among other projects, we figured out a way to have people work on sermon transcriptions from home. One staff member worked out the process for using YouTube to automatically generate a transcript of an uploaded file, and then how to transfer that transcript to a Word document for editing. She's responsible for doing that for each sermon as it's assigned to a staff member. Our Associate Archivist created a style sheet and coordinates the assignment of transcripts, while the Project Archivist adds them to the related recording on Illumira.

It seems odd to say this, but COVID-19 actually had a silver lining for our Archives. We've initiated projects that would either not have been started or been worked on at a much slower pace due to other demands on our time. As we started the different projects to keep our staff busy and employed, supervisors from other library units asked if we had any work their part-time staff (mostly students) could do. 
We have provided work for up to ten part-time staffers from other units during the past fifteen months, although the transcript project has only recently been assigned to them. It's a large task that will be ongoing for quite a while. On the plus side for the project, the library staff will only be partially in person through mid-January 2022, so we have several more months of remote workers needing something to do from home. Transcript editing is perfectly suited for remote work. In addition, the Jones family has followed through with their promise of a donation to support the project, so we will be re-hiring the Project Archivist, who knows the collection best, to also work on the transcripts.

One of Rev. Jones' daughters, Jennifer Jones Austin, has recently republished a book of her father's sermons, God in the Ghetto: A Prophetic Word Revisited, with essays from several notable leaders, including Rev. Al Sharpton and Rev. William J. Barber II. For Mrs. Austin's book launch events, we are providing her with clips from two of the digitized sermons, and she will promote the digital archive at the same time.

Two of the clips requested by Mrs. Austin were from the sermon "The Flag and the Cross." We do not have a date for this recording, but it is sometime during Ronald Reagan's presidency. In the sermon, Jones urges the church and all Christians to stop turning a blind eye to the sins of the state, and he mentions the need to pledge allegiance to the cross instead of the flag.

The first clip is from 27:38-30:13 of this recording: https://brooklyn.illumira.net/show.php?pid=njcore:179263

The second clip is from 13:18-16:20 of this recording: https://brooklyn.illumira.net/show.php?pid=njcore:179258

In addition to the Illumira site and the Atla Digital Library (https:// dl.atla.com/), researchers can discover and access the sermons from the Archives' website (https://libguides.brooklyn.cuny.edu/c. php?g=1135687). This page has links to the Illumira page, an example of a sermon with a transcript, and also a link to the finding aid for the entire Jones collection (https://archives.brooklyn.cuny.edu/ repositories/2/resources/2).

Once you click on the finding aid link, on the right you can see last sub-group of materials is called Digital Files. This subgroup divides the sermons into video or audio recordings, and clicking on 
a title will open the file. Under Scope and Contents there is a link to the recording in Illumira. For example, click on "Keep the Fire Burning”: https://archives.brooklyn.cuny.edu/repositories/2/archival_objects/12765

The collection is cataloged in the CUNY catalog and is in WorldCat. Although not one of the grant deliverables, we planned on having an exhibit and formal launch event for the collection. At present these will have to wait for the Brooklyn College Campus to fully reopen, hopefully in Spring 2022.

I hope you will share this new digital resource with your library patrons. 